\title{
DIREITO CONTRATUAL, JUSTIÇA DISTRIBUTIVA E VIRTUDES CÍVICAS
}

\author{
CONTRACTUAL LAW, DISTRIBUTIVE JUSTICE AND CIVIC VIRTUES
}

Leandro Martins Zanitelli*

\section{RESUMO}

O artigo responde a uma crítica de Seana Shiffrin ao direito contratual. Nela, a autora afirma que certa leniência com o inadimplemento contratual leva o direito a divergir da moral respeitante a promessas, o que atenta contra o interesse dos cidadãos em se desenvolverem moralmente e conspira contra uma cultura igualitária. Afirma-se que Shiffrin erra ao supor que leis mais severas forjem cidadãos mais virtuosos, mas que sua crítica tem o mérito de ressaltar a influência do direito sobre as preferências dos cidadãos, ponto negligenciado por teorias do direito contratual associadas à justiça distributiva.

PALAVRAS-CHAVE: Contratos. Shiffrin. Inadimplemento. Virtudes cívicas. Justiça distributiva.

\section{ABSTRACT}

The paper answers to Seana Shiffrin's criticisms against contract law. Shiffrin states that lenience towards breach renders contract law divergent from moral prescriptions respecting promises, thus jeopardizing citizens' interest in moral development and the development of an egalitarian culture. It is argued that Shiffrin is mistaken by assuming that more severe laws necessarily give rise to virtuous citizens. Shiffrin's criticisms are valuable, nonetheless, in stressing law's influence over citizens' preferences, a point commonly neglected by contract law theories associated with distributive justice.

KEYWORDS: Contracts. Shiffrin. Breach. Civic virtues. Distributive justice.

\section{INTRODUÇÃO}

Este artigo trata do problema da divergência entre contrato e promessa. Há alguns anos, Seana Shiffrin (2007) criticou o direito contratual norte-americano pelo tratamento frouxo dispensado ao inadimplemento de contratos. Segundo Shiffrin, em síntese, o direito contratual dos EUA falha moralmente por não tratar as promessas que as partes de um contrato fazem uma à outra com a mesma seriedade com que a moral requer que promessas sejam tratadas. A divergência entre contrato e promessa a que se refere Shiffrin é, portanto,

\footnotetext{
* Doutor em Direito pela UFRGS. Professor Adjunto na Faculdade de Direito da UFMG. E-mail: leandrozanitelli@gmail.com.
} 
uma divergência entre a regulação jurídica dos contratos (mais precisamente, do inadimplemento contratual) e as normas morais interpessoais ${ }^{1}$ aplicáveis às promessas.

O artigo de Shiffrin provocou inúmeras respostas (MURPHY, 2007; LIPSHAW, 2008; FELDMAN, 2009; KRAUS, 2009; MARKOVITZ; SCHWARTZ, 2011; KATZ, 2012). Meu objetivo aqui é, primeiro, responder, também, à crítica de Shiffrin que se aplica, em boa medida, ao direito brasileiro. Segundo, quero mostrar que, embora objetáveis, os argumentos de Shiffrin chamam a atenção para a necessidade de uma revisão importante em concepções do direito contratual baseadas em justiça distributiva.

Tendo em vista o segundo dos objetivos recém-enunciados, a primeira seção deste artigo distingue teorias do direito contratual como justiça distributiva (ou "distributivistas") de outras duas famílias de teorias rivais, teorias deontológicas e teorias do direito contratual como justiça corretiva. Na segunda seção, são apresentados os argumentos de Shiffrin sobre a divergência entre contrato e promessa, enquanto a terceira seção responde a esses argumentos. $\mathrm{Na}$ quarta e última seção, mostra-se por que, apesar de falho, o ataque de Shiffrin ao direito contratual norte-americano merece a atenção de distributivistas.

\section{TEORIAS DISTRIBUTIVISTAS, CORRETIVISTAS E DEONTOLÓGICAS}

As três famílias ou classes de teorias a que se refere esta seção dizem respeito à justificação moral do direito contratual. Mais precisamente, elas respondem à questão de saber se deve haver um direito contratual e, em caso afirmativo, qual deve ser o conteúdo das suas normas. Elas são, nesse sentido, teorias normativas, o que as diferencia de teorias causais (que se ocupam com os processos históricos dos quais o direito contratual é resultado) e interpretativas (ocupadas com a descrição do direito contratual vigente em certa época e lugar).

Comecemos com as teorias distributivistas. Segundo essas teorias, o direito contratual se justifica moralmente se e à medida que atenda a um ideal de justiça distributiva. Ideais de justiça distributiva podem variar em relação ao que querem ver distribuído (bem-estar, liberdades, oportunidades, etc.) e a como querem que essa distribuição se dê (igual para todos, em uma medida suficiente para todos, na maior medida possível para os que estiverem em pior situação, etc.). Em qualquer de suas versões, o distributivismo atribui aos contratos e às

\footnotetext{
${ }^{1}$ Usa-se o termo "interpessoal" para referir o fato de as normas em questão se aplicarem diretamente às promessas, e não a instituições sociais, como o direito, de que elas sejam objeto.
} 
normas que os regem um valor instrumental. O direito contratual deve ser conformado de tal maneira a que os contratos deem lugar a um estado distributivo ideal (ou o mais próximo possível disso).

Na literatura recente, o principal caso de distributivismo é, sem dúvida, o da economia dos contratos, a qual pode ser dividida em duas vertentes, a do neoinstitucionalismo (WILLIAMSON, 1985; NORTH, 1990) e a da análise econômica do direito (POSNER, 1998[1973]). Enquanto a primeira trata o direito contratual como um dentre vários (no dizer de Williamson) "mecanismos de governança”, isto é, como uma dentre várias soluções para o problema dos custos de transação, a segunda atenta para o conteúdo das normas jurídicas (sem necessariamente ignorar, contudo, a relação entre essas normas e outros mecanismos de governança). Em ambos os casos, o ideal distributivo a serviço do qual se põe o direito contratual é o da eficiência.

Tradicionalmente, consideram-se a eficiência e a igualdade como objetivos rivais. Não há espaço aqui para entrar em detalhes a respeito, de maneira que me contentarei com um exemplo simples. Uma conhecida concepção de eficiência é a de Pareto, segundo a qual um estado de coisas é eficiente se não é possível melhorar a situação de um sujeito sem piorar, com isso, a de algum outro. Considere então um estado de coisas inicial $x$ em que A e B possuem, respectivamente, 100 e 2 do que queremos distribuir (seja lá o que for). Se pudermos passar de $x$ para um outro estado de coisas $y$ no qual A tenha 200 e B continue com 2, então $x$ é ineficiente (há uma mudança possível que melhora a situação de um dos sujeitos, A, sem piorar a do outro). Mais ainda, se, depois de chegar a $y$, não for possível melhorar a situação de uma das partes sem piorar a da outra, $y$ será eficiente no sentido de Pareto, a despeito de a diferença entre A e B ser maior em $y$ do que em $x$.

Em um sentido amplo, podemos chamar de igualitários ideais de justiça distributiva que, em contraste com ideais eficientistas, não sejam indiferentes à posição relativa dos sujeitos (ainda que não requeiram que a situação dos sujeitos considerados seja estritamente igual). Em comparação com o neoinstitucionalismo e a análise econômica do direito, a literatura sobre igualitarismo contratual (no sentido recém-explicitado) é muito menos volumosa, embora conte com obras importantes (ACKERMAN, 1971; KRONMAN, 1980; KENNEDY, 1982). Mais recentemente, uma particular concepção de igualitarismo contratual, baseada na teoria da justiça de Rawls (1999[1971]), tem sido defendida (KORDANA; TABACHNICK, 2005; SCHEFFLER, 2015; KLIJNSMA, 2015). 
No caso das teorias corretivistas (GORDLEY, 1981; BENSON, 1989; WEINRIB, 1995), a justificação para a existência de obrigações contratuais se dá em termos estritamente bilaterais. Como obrigação fundada em justiça corretiva (ou comutativa), a obrigação de A para com B é justificada à base da particular relação entre A e B (por exemplo, no fato de A ter dado ou prometido dar algo a B). É irrelevante, em tal caso, tudo o que não diga respeito à relação entre $\mathrm{A}$ e $\mathrm{B}$, tal como a situação de terceiros ou mesmo a de $\mathrm{A}$ e $\mathrm{B}$ quanto à distribuição de algum bem (por exemplo, o quanto A e B são ricos).

Por fim, teorias deontológicas (e.g., FRIED, 1981; BARNETT, 1986) relacionam a moralidade do direito contratual a certos direitos anteriores ao contrato. Contratos (e as obrigações que deles decorrem) justificam-se, segundo essas teorias, como exercício legítimo de direitos conferidos às partes. O uso do termo "deontológico" para essas teorias pode provocar um mal-entendido, já que, usualmente, concepções deontológicas de moralidade se opõem a concepções consequencialistas. Enquanto para o consequencialismo o status moral de um ato depende tão-somente das suas consequências, o deontologismo reputa certos atos como proibidos, obrigatórios ou permitidos a priori, isto é, de modo independente (em certa medida, ao menos) das suas consequências. Há um risco de confusão aqui porque certas teorias distributivistas sobre o direito contratual podem se basear em concepções morais deontológicas (tal como, por exemplo, a da justiça de Rawls). A diferença é que o distributivismo contratual (no sentido em que a expressão é usada aqui) não é indiferente aos efeitos (de curto ou longo prazo) dos contratos para a distribuição do que se considera relevante. As concepções aqui chamadas de deontológicas, em contrapartida, mostram-se indiferentes a esses resultados. Para essas concepções, as obrigações contratuais se justificam com base nos direitos prévios das partes e de maneira completamente independente da distribuição (de riqueza, liberdades, oportunidades, etc.) a que o exercício da liberdade contratual dê lugar.

\section{SHIFFRIN E A DIVERGÊNCIA ENTRE CONTRATO E PROMESSA}

Shiffrin (2007) começa sua crítica ao direito contratual norte-americano com uma distinção entre dois pontos de vista sobre a relação entre moral interpessoal e direito (p. 713). ${ }^{2}$ Para um desses pontos de vista, que ela chama de "reflexivo", o conteúdo do direito deve corresponder, tanto quanto possível, às normas de moralidade interpessoal. Se uma dessas

\footnotetext{
${ }^{2}$ Números de página entre parênteses nesta seção se referem a Shiffrin (2007).
} 
normas ordena que A cumpra a promessa que fez a B sob certas circunstâncias, o cumprimento de tal promessa, de acordo com a posição reflexiva, também deve ser juridicamente obrigatório. Para o ponto de vista "separatista", em contraste, os domínios do direito e da moral são independentes. Não há, portanto, segundo esse ponto de vista, nenhuma razão a priori para que o direito contratual mimetize normas morais sobre promessas.

Shiffrin defende uma posição intermediária, ou "acomodacionista", entre o refletivismo e o separatismo (p. 713). O refletivismo ignora que uma certa independência em relação à moral interpessoal pode ser necessária a que o direito atenda a princípios e objetivos que lhe são próprios (p. 714). A subserviência do direito à moralidade também é incompatível com o liberalismo (p. 714). Por outro lado, mesmo liberais, argumenta Shiffrin, deveriam rejeitar o separatismo, porque não é um corolário do liberalismo que a justiça e o direito independam de agentes com certas virtudes (p. 714). Um exemplo é a teoria da justiça de Rawls, que pressupõe que os cidadãos tenham desenvolvido as capacidades morais que estão à base da capacidade para um senso de justiça (p. 714). ${ }^{3}$ Para Shiffrin, entre as referidas capacidades morais está uma certa compreensão sobre a moralidade das promessas. Sem uma cultura da promessa e os hábitos morais e sensibilidades que a acompanham, ela diz, é duvidoso que a justiça social vingue ou que um sistema jurídico seja espontaneamente obedecido (p. 714).

Para o acomodacionismo, portanto, quando uma prática como a da promessa é governada ao mesmo tempo por normas jurídicas e morais, não é preciso que haja uma estrita correspondência entre o conteúdo de umas e outras. Deve-se cuidar, no entanto, para que o direito seja em alguma medida sensível às demandas morais aplicáveis a essas práticas, de modo que obedecer às normas jurídicas não se torne um empecilho considerável ao desenvolvimento das capacidades morais (p. 715).

Depois de argumentar que o acomodacionismo não precisa se basear em uma certa concepção do bem e não é, portanto, inconciliável com o liberalismo (p. 716-717), Shiffrin enuncia as três implicações do seu ponto de vista para o direito contratual. Para casos, como o dos contratos, em que a regulação jurídica incida sobre relações por si sós carregadas de significado moral, o que se requer do direito é, primeiro, que o cumprimento às suas normas não seja incompatível com uma vida minimamente virtuosa (p. 718). ${ }^{4}$ Segundo, as normas

\footnotetext{
${ }^{3}$ Sobre a capacidade para um senso de justiça, ver Rawls (1999[1971], cap. 8).

4 "First, what legal rules directly require agents to do or to refrain from doing should not, as a general matter, be inconsistent with leading a life of at least minimal moral virtue."
} 
jurídicas e as razões que as embasam devem ser públicas e tais que, para os cidadãos, o conhecimento dessas razões não atrapalhe a aquisição e conservação de virtudes. ${ }^{5}$ Terceiro, o direito deve dar lugar a práticas e a uma cultura que apoiem um caráter moralmente virtuoso (p. 719). ${ }^{6}$ Isso não implica necessariamente tornar a virtude juridicamente obrigatória (o que pode até ser contraproducente), mas pode requerer que o direito não incentive condutas que lhe sejam contrárias (p. 719).

Segundo Shiffrin, o direito contratual norte-americano possui características que violam a segunda e a terceira das condições recém-enunciadas. ${ }^{7}$ Do ponto de vista moral, quem promete algo deve fazer o que prometeu. Substituir o cumprimento da promessa por uma indenização somente é moralmente admissível excepcionalmente - por exemplo, se o cumprimento se tornou impossível ou muito difícil. No direito norte-americano, entretanto, ao invés da execução específica (specific performance), a consequência para o inadimplemento de um contrato é a indenização (expectation damages ${ }^{8}$ ) (p. 722-723).

Outras causas de divergência entre o direito contratual e normas morais sobre promessas são a recusa a aplicar indenizações punitivas em casos de inadimplemento intencional (p. 723), a regra de Hadley, que limita a indenização a danos que podiam ter sido previstos pela parte inadimplente à época em que o contrato ocorreu (p. 724), e a doutrina da mitigação (mitigation doctrine), que também reputa não indenizáveis os danos que o credor poderia ter evitado (p. 724). Para Shiffrin, essas normas são incondizentes com a gravidade moral do descumprimento de uma promessa. Sob a ótica moral, é estranho que o promitente não se sujeite a uma punição pelo descumprimento e nem sequer tenha de arcar com todas as consequências do seu ato (p. 724). É estranho, também, que seja do promissário o ônus de agir para atenuar as consequências do inadimplemento (p. 725).

Shiffrin entende que as normas citadas violam a segunda das condições mencionadas porque se apoiam no argumento do inadimplemento eficiente (efficient breach) (p. 730). Shiffrin distingue duas versões desse argumento. Na versão "forte", diz-se que o inadimplemento eficiente é moralmente desejável devido às suas consequências para o bem-

\footnotetext{
5 "Second, the law and its rationale should be transparent and accessible to the moral agent. Moreover, their acceptance by the agent should be compatible with her developing and maintaining moral virtue."

6 "Third, the culture and practices facilitated by law should be compatible with a culture that supports morally virtuous character."

${ }^{7}$ A primeira condição é atendida à medida que o direito não force as pessoas a se comportarem imoralmente. Para o direito contratual basta, portanto, a grosso modo, que o inadimplemento contratual não seja obrigatório ( $\mathrm{p}$. 729-730).

${ }^{8} \mathrm{O}$ conceito de expectation damages é similar ao de indenização pelo interesse positivo. Para o cálculo dessa indenização, considera-se a situação em que a vítima de inadimplemento estaria caso a obrigação tivesse sido cumprida.
} 
estar social (p. 730). ${ }^{9} \mathrm{Na}$ versão fraca, embora se admita que o descumprimento, apesar de eficiente, seja contrário à moral, afirma-se que, para o direito, isso é irrelevante (p. 730). Segundo Shiffrin, nenhuma das versões do argumento é aceitável para o agente virtuoso. Em relação à versão forte, não é possível acreditar ao mesmo tempo que uma promessa vincule e que seja tolerável descumpri-la sempre que o bem-estar social assim o requeira (p. 731). A versão fraca tampouco é palatável, porque força os cidadãos a aceitar que o direito se justifique por objetivos cuja realização pode estar em contradição com certos compromissos morais fundamentais (p. 732). ${ }^{10}$

Shiffrin esclarece que o problema com o argumento do inadimplemento ineficiente é não apenas que ele diverge do que a moral dita a respeito das promessas, como também não apelar para nenhuma particularidade da regulação jurídica a fim de justificar a discrepância com a moral. Argumentos que chamem a atenção, por exemplo, para o custo de realizar a execução forçada específica da obrigação ou para a possível afronta à liberdade individual a que ela dá causa diferem do argumento do inadimplemento eficiente porque não põem em dúvida a imoralidade do descumprimento de uma promessa (ou não proclamam a indiferença do direito a essa imoralidade) e, por isso, não seriam igualmente objetáveis (p. 733). Para Shiffrin, porém, não parece haver argumentos como os recém-referidos que deem conta da notável divergência entre o direito contratual norte-americano e as prescrições morais sobre promessas (p. 733-737).

Com relação à terceira condição, Shiffrin (p. 740) manifesta o temor de que a leniência com o inadimplemento de contratos (e o argumento de eficiência que a embasa) dê lugar a uma cultura inóspita a comportamentos conformes à moral, seja simplesmente pelo fato de esses comportamentos não serem juridicamente obrigatórios, seja porque acabem tratados como exóticos. ${ }^{11}$ Nossos atos, diz Shiffrin, são, em boa medida, determinados por predisposições com raiz em deliberações passadas (p. 741). Essas deliberações são

\footnotetext{
${ }^{9}$ Para ficar com um exemplo, a indenização poderia ser defendida com um argumento de eficiência, porque não força que ocorra o cumprimento em casos nos quais o seu custo para o devedor seja maior do que o benefício para o credor. O ponto de Shiffrin, no entanto, não é que as normas do direito norteamericano sejam, de fato, eficientes, o que é duvidoso (ver POSNER, 2003, p. 834-839), mas sim que o argumento de eficiência seja, aparentemente, o único disponível para defender as normas em questão.

${ }^{10}$ Ver Shiffrin (p. 732): “A virtuous agent can surely accept that there may be good aspects to wrongful breach on certain occasions. Yet, if such breach is indeed, all things considered, wrong, a virtuous agent cannot accept the economic benefits of breach as constituting a sufficient, or even a partial, contributory justification for the law's content."

${ }^{11}$ Shiffrin (p. 740): "the rule and its justification may play a role in creating a wider culture in which pressure develops not to comply with the moral commitment, whether just because it is not legally required or because the legal permission spawns cultural habits that render moral compliance precious or alien."
} 
influenciadas, por sua vez, por instituições sociais e pelos comportamentos que essas instituições encorajam (p. 741). O fato de nosso comportamento depender em considerável medida de reações cognitivas e emocionais forjadas ao longo do tempo desafia a suposição de que sejamos capazes de compartimentar nossas decisões, de tal maneira que a permissividade jurídica não distorça nossa visão acerca da imoralidade de certos comportamentos.

Antes de passarmos à crítica aos argumentos de Shiffrin, uma breve nota sobre a sua aplicabilidade ao direito brasileiro. Diferentemente do que ocorre nos EUA, no Brasil a execução forçada específica é admitida para as obrigações contratuais em geral (CPC, arts. 806 a 823), excetuando-se os casos em que seja impossível (CC, arts. 238, 239, 248 e 250) ${ }^{12}$ e nos quais a prestação só seja realizável por determinada pessoa (CPC, art. 821). De resto, as características que Shiffrin tem em vista também são encontradas no direito brasileiro. Não há, entre nós, previsão legal para indenização punitiva por inadimplemento contratual. Argumentos punitivos (por exemplo, sobre a reprovabilidade da conduta ou a riqueza do réu) são, por vezes, empregados na liquidação de danos extrapatrimoniais, mas a jurisprudência é, em geral, bastante restritiva quanto a condenar o contratante inadimplente a pagar por tais danos. A ideia de que a vítima deve tomar as medidas que razoavelmente estiverem ao seu alcance para amenizar as consequências do inadimplemento é atualmente bem aceita, inclusive por influência dos sistemas jurídicos de common law (FRADERA, 2004; Enunciado $\mathrm{n}^{\mathrm{o}} 169$ da III Jornada de Direito Civil do Conselho da Justiça Federal). Por fim, chega-se a resultados parecidos com o da regra de Hadley mediante o requisito do nexo causalidade e sua interpretação como causalidade direta ou imediata (ver TEPEDINO, 2002).

\section{UMA CRÍTICA A SHIFFRIN}

As acusações que Shiffrin faz ao direito contratual norte-americano são, em síntese, as seguintes. A primeira é a de atentar contra um interesse fundamental dos cidadãos em se desenvolverem moralmente ao repousar em uma justificativa, o inadimplemento eficiente, antitética a prescrições morais quanto a promessas. Segundo, ao assim fazer, o direito contratual atrapalha o florescimento de uma cultura de respeito às promessas sem a qual é duvidoso que possam vicejar instituições justas e estáveis.

\footnotetext{
12 "Possível" se entende como "razoavelmente possível". Uma acentuada dificuldade se equipara, portanto, à impossibilidade.
} 
No que segue, aceitarei algumas premissas dos argumentos de Shiffrin, a saber, em primeiro lugar, a de que os cidadãos possuem um interesse em se desenvolverem moralmente e que, todo o restante sendo igual, devemos preferir as instituições que atendam a esse interesse às que o contrariem. Segundo, concordarei também que, para a justiça, a estabilidade que importa é a que Rawls (2001, p. 185-186) chama de liberal, porque conseguida não mediante a ameaça de sanções, mas pelo endosso de cidadãos que possuem um senso de justiça, de modo que o papel das instituições em fazer aflorar esse senso de justiça não pode ser negligenciado.

Tenho, ao todo, três ressalvas a fazer a Shiffrin. As duas primeiras são mais emendas do que objeções, propriamente. A terceira, porém, é mais séria. Vamos a elas.

Primeiro, Shiffrin se atém às disposições sobre as consequências do inadimplemento, ignorando eventuais dificuldades com que os contratantes se deparam para fazer valer essas disposições. Pode-se imaginar um país em que o direito contratual e suas justificativas se coadunam com o status moral das promessas, mas cuja administração da justiça é corrupta, seletiva e cara. É plausível que um sistema jurídico com essas características seja ainda pior, para os fins que Shiffrin tem em vista, do que outro cujas disposições, embora mais lenientes, são aplicadas de maneira equânime e célere. Para o desenvolvimento das capacidades morais dos cidadãos e para o florescimento de uma cultura da promessa, podem ser igual ou até mais perniciosas instituições que, hipocritamente, enalteçam a palavra dada sem serem capazes de fazê-la valer.

Segundo, a análise de Shiffrin desconsidera a importância de outros mecanismos de governança que não o direito (estatal) contratual. Há uma farta literatura empírica sobre meios extralegais para o cumprimento de contratos. Esses meios podem ter lugar à falta de instituições legais de boa qualidade (GREIF, 1989) ou, simplesmente, ser preferidos pelas partes a despeito de haver meios formais de execução relativamente eficazes à disposição (CHARNY, 1990; BERNSTEIN, 1992). Contra Shiffrin, pode-se ponderar, pois, que um direito contratual que não trata o descumprimento de uma promessa com a seriedade desejada não necessariamente inibe o desenvolvimento moral dos agentes ou dá lugar a hábitos imorais. Tanto no que se refere à educação moral dos agentes quanto a uma cultura de respeito às promessas, o direito contratual terá pouca importância caso seja, com frequência, suplantado por outros meios de coerção ou, simplesmente, ignorado.

As observações recém feitas são, contudo, meros reparos. Em sua defesa, Shiffrin poderia dizer que sua análise se circunscreve ao direito contratual. Mesmo que haja outros 
fatores importantes para forjar cidadãos virtuosos e a cultura de respeito a promessas imprescindível para uma ordem social justa, tal como a observância ao Estado de Direito, nada impede que pensemos sobre a conformação do direito contratual mais propensa à realização dos referidos objetivos. Mais ainda, do fato de as normas jurídicas serem com alguma frequência ignoradas pelos contratantes não segue nenhuma razão para preferirmos que essas normas se coadunem menos com as prescrições morais relativas às promessas. Quando muito, isso leva à conclusão de que o problema da divergência pode ser menos grave do que Shiffrin sugere.

Outro, e mais importante, reparo é que Shiffrin presume uma relação entre o direito e a vida moral dos cidadãos demasiadamente simples. Para ela, se as normas jurídicas e suas respectivas justificativas falharem em tratar o descumprimento de promessas com a seriedade devida, os cidadãos também propenderão a fazê-lo. Embora não seja determinista, pois não chega a afirmar que a divergência entre contrato e promessa dê lugar fatalmente a cidadãos imorais e a uma cultura incompatível com a prática da promessa, a análise de Shiffrin peca por não levar em consideração a hipótese contrária, de que sanções legais inibam a virtude ao invés de fomentá-la.

A literatura sobre os efeitos do direito e de suas sanções sobre o comportamento não põe por terra, necessariamente, as objeções quanto à divergência entre contrato e promessa, mas revela um cenário muito mais indefinido do que o sugerido por Shiffrin. O que se dá como certo (BOWLES, 2016) - e, quanto a isso, Shiffrin está, sem dúvida, de acordo - é que as sanções podem ser mais do que mero incentivos, isto é, podem fazer mais do que apenas alterar o custo esperado de certas condutas. Sanções também podem influenciar o comportamento dos cidadãos ao alterar suas crenças e preferências.

Em particular, está de acordo com Shiffrin - e, em particular, com a sua crítica à indenização como remédio principal para o inadimplemento - a hipótese de que a sanção pecuniária, ao "precificar" o comportamento que dela é objeto, pode fazê-lo parecer menos reprovável aos olhos do agente e de outras pessoas. Essa hipótese explica o resultado do experimento de Gneezy e Rustichini (2000) em creches de Israel. Nele, foi cominada uma multa para os pais que se atrasassem para buscar seus filhos na creche. Ao invés de reduzi-los, a penalidade fez com que os atrasos se tornassem mais frequentes, um efeito que persistiu 
mesmo depois de ela ser abolida. Pode ser que a multa tenha feito os pais perceberem o atraso como uma commodity, isto é, como algo que é aceitável comprar tanto quanto se queira. ${ }^{13}$

O problema das sanções pode não se resumir, contudo, à precificação de comportamentos e às consequências que daí decorrem. Cogita-se, também, que as sanções surtam efeitos "anômalos" devido às informações que veiculam. Tanto o legislador, ao cominar uma sanção, quanto a parte de um contrato, ao propor uma cláusula penal ou simplesmente tomar providências para que o contrato seja judicialmente executável (por exemplo, demandar que seja feito por escrito), sujeitam-se a provocar uma reação negativa pela informação que o seu comportamento (ainda que não intencionalmente) transmita. Sanções, como diz Bowles (2016, p. 83-86), podem ser recebidas como más notícias e, consequentemente, causar reações indesejadas.

O que as sanções informam pode, é claro, variar. Aqui, a hipótese que interessa é que a sanção informe desconfiança em relação ao agente contra o qual é cominada. Ao perceber a desconfiança da outra parte (que chamarei de "principal"), o agente pode "responder na mesma moeda", isto é, desconfiar também (HEROLD, 2010; CHOU et al., 2011). O problema da desconfiança mútua é que ela leva agentes que sejam "cooperadores condicionais" (FISCHBACHER et al., 2001) a se comportarem de maneira autointeressada. Na literatura, designam-se como cooperadores condicionais os sujeitos dispostos a renunciar à maximização da própria utilidade em prol do bem comum, desde que outros também o façam (ou, ao menos, desde que acreditem que outros também o farão). Para cooperadores condicionais, uma manifestação de desconfiança pode ser o "gatilho" para uma conduta egoísta (FEHR; LIST, 2004; FALK; KOSFELD, 2004; FALK; KOSFELD, 2006).

No que se refere à eficiência, o problema do efeito desvirtuante das sanções é que o resultado (ou payoff) do principal costuma ser uma função da motivação intrínseca (isto é, independente de incentivos) do agente. Há, em geral, características do comportamento do agente que não são "contratáveis", isto é, que não é possível especificar de antemão ou que o principal é incapaz de observar. Daí porque, para o principal, em certas circunstâncias, pode ser mais vantajoso confiar no agente (evitando solapar sua motivação intrínseca a cooperar) do que ameaçá-lo. É sintomático, a respeito, o que Fehr e List (2004) verificaram em um experimento com um "jogo de confiança” no qual o principal dependia do desempenho do

\footnotetext{
${ }^{13}$ A explicação baseada em normas sociais não é a única possível. V. Gneezy e Rustichini (2000, p. 8-14).
} 
agente e podia manifestar a sua confiança nele. ${ }^{14}$ Os autores compararam o comportamento de CEOs e estudantes no jogo e descobriram que, ao atuarem como principais, os primeiros confiaram com mais frequência e conseguiram resultados melhores, um indício de que a confiança costuma ser recompensada também no dia-a-dia negocial.

O problema de a cominação de sanção levar o agente a se comportar autointeressadamente vai além, contudo, da ineficiência daí resultante. Retornando à divergência entre contrato e promessa: Shiffrin alega, como visto, que um direito contratual pouco rígido e a justificativa que o apoia são pouco propensos ao florescimento de virtudes cívicas. Considere, então, uma possível consequência de um direito contratual sem as características que Shiffrin abomina - um direito que admita, em geral, a execução específica e sob o qual as consequências do inadimplemento não sejam abrandadas pela proibição à indenização punitiva e normas como a de Harley e da doutrina da mitigação. Ao contratar, uma das decisões que as partes devem tomar é sobre se farão ou não o contrato de maneira a permitir (ou facilitar) a sua execução forçada (por exemplo, pelo uso da forma escrita ou mediante um detalhamento das cláusulas). Quando uma das partes insta a outra a contratar de maneira a ensejar a execução forçada, é bem possível que esse gesto seja interpretado do modo descrito acima, isto é, como uma manifestação de desconfiança. É plausível, pois, que uma diferença entre um direito contratual mais e um menos leniente com o inadimplemento seja que, sob o segundo, a desconfiança manifestada ao contratar de maneira que permita a execução forçada seja mais inequívoca.

Em outros termos. Repare, então, primeiro, que é concebível um contrato cuja celebração seja uma manifestação de confiança inequívoca. Como tal seria de considerar o caso de um contrato não apenas insuscetível à execução judicial (seja porque desatenda a algum requisito para tanto, seja porque não se sujeite a jurisdição alguma), mas em que falte qualquer outro incentivo, como a reputação, para o cumprimento. Poucos contratos são assim,

\footnotetext{
${ }^{14} \mathrm{O}$ jogo consistia no seguinte. O principal recebia inicialmente 10 fichas (trocáveis, no fim do experimento, por dinheiro), tendo então de decidir se transferiria parte ou a totalidade dessas fichas para um agente (as partes permaneceriam anônimas do início ao fim do experimento). A cada ficha transferida para o agente, mais duas eram acrescentadas ao "bolo" pelos organizadores do experimento. O agente devia decidir, então, a quantidade de fichas a ser devolvida para o principal (por exemplo, em um caso no qual o principal transferisse 5 fichas, o agente receberia 15 fichas e decidiria quantas delas guardaria para si e quantas devolveria ao principal). Em uma das versões do jogo, Fehr e List acrescentaram a possibilidade de o principal cominar uma multa para o agente (perda de 4 fichas) caso uma certa quantidade de fichas (estipulada pelo principal) não lhe fosse devolvida. Nessa versão, os principais que decidiram renunciar antecipadamente à penalidade (fato sabido pelos agentes) tiveram resultados melhores, inclusive se comparados aos de uma versão do jogo na qual a punição não era prevista. A conclusão é que a decisão de alguns principais de renunciar à multa (e a confiança que ela manifesta) teve um efeito positivo sobre o comportamento dos agentes.
} 
mas o importante é a ideia, que esse caso extremo sugere, de que os contratos ocupam um contínuo em que a oportunidade de manifestar confiança se reduz à medida que se robustece o incentivo para o cumprimento. Nesse contínuo, um contrato executável sob um direito "fraco" (isto é, com as características deploradas por Shiffrin) ocupa uma posição intermediária, emitindo uma mensagem um tanto truncada. É verdade que o credor poderia ter aberto mão de atender aos requisitos que tornam o contrato executável (presumo aqui que isso era possível), com o que a decisão de contratar seria mais facilmente percebida pelo devedor como um ato de confiança. ${ }^{15}$ Em se tratando de um direito pouco rígido, contudo, a decisão de contratar também tem um outro sentido. Como as normas jurídicas aplicáveis não resguardam plenamente os interesses do credor, essa decisão também é uma manifestação de confiança, em particular se não há outros meios de coação (por exemplo, em casos nos quais a reputação não seja importante para o devedor). Em contrapartida, com um direito contratual forte (isto é, implacável com o inadimplemento), a chance de a decisão de contratar manifestar confiança diminui. $^{16}$

Lembre-se de que a acusação de Shiffrin contra o direito contratual é dupla. Normas frouxas e o argumento do inadimplemento eficiente atentam contra o interesse fundamental dos agentes em se desenvolverem moralmente e podem ter consequências culturais perversas para a justiça. Um direito contratual forte, porém, sujeita-se, em princípio, a acusações similares. Não é absurdo supor que virtudes fiquem mais difíceis de adquirir em um meio no qual as pessoas se comportam como se essas virtudes não existissem (ou fossem raras). Ao reduzir a oportunidade para que as pessoas manifestem confiança umas nas outras, um direito contratual rigoroso também se põe em tensão, portanto, com o interesse dos cidadãos em seu desenvolvimento moral e com o objetivo de uma cultura da promessa. ${ }^{17}$

Não é fácil dizer qual efeito deletério é mais pronunciado, se o de uma legislação que admite mais escusas para o descumprimento de promessas do que é aceitável, moralmente

\footnotetext{
${ }^{15}$ Para a ideia de que os contratantes podem ter a intenção de fazer com que algumas partes da avença sejam executáveis coercivamente, enquanto outras dependam de mecanismos "relacionais" de governança, inclusive a motivação intrínseca a cumprir a palavra dada, ver Kraus e Scott (2009).

${ }^{16} \mathrm{Em}$ resposta, Shiffrin poderia dizer que um direito mais rigoroso só dificulta que os contratantes manifestem confiança um no outro se as suas normas forem cogentes, isto é, se, ao contratar, as partes não estiverem aptas a estipular um regime mais brando. O problema é que a proposta de optar por um regime assim pode ser malvista pela parte a quem é feita. Por exemplo, ao saber que A deseja uma penalidade mais suave para o inadimplemento, B pode inferir que A tem inclinação para inadimplir ou é, de um modo geral, pouco confiável. Antecipando que a proposta de mudança de regime pode surtir esse efeito em B, A pode, então, abster-se de fazê-la. Sobre o potencial de propostas para emitir sinais sobre características do proponente e a dificuldade que daí decorre para derrogar normas dispositivas, ver Spier (1992); Ben-Shahar e Pottow (2006).

${ }^{17}$ Para a ideia de que leis que manifestem desconfiança em relação aos cidadãos podem ter um efeito pernicioso para as virtudes, ver Frey (1997).
} 
falando, ou de uma outra que dispensa tratamento implacável para os mesmos casos e, ao fazê-lo, torna manifestações de confiança mais difíceis. O objetivo do argumento acima é demonstrar que Shiffrin está errada não ao afirmar que a divergência entre contrato e promessa é indesejável, mas em simplesmente desconsiderar uma hipótese contrária.

\section{CONCLUSÃO}

Os argumentos de Shiffrin sobre a divergência entre contrato e promessa podem interessar teorias distributivistas do direito contratual. Para entender por quê, repare, em primeiro lugar, que essas teorias não dizem necessariamente respeito apenas à distribuição de riqueza, renda ou bem-estar. Entre os bens dos quais um ideal distributivo se ocupa podem estar certas virtudes, de modo a que se requeira que os cidadãos possuam essas virtudes em alguma medida ou contem com um meio propício para adquiri-las. ${ }^{18}$ Para teorias da justiça distributiva com esse feitio, a acusação que Shiffrin faz ao direito contratual norte-americano é, muito provavelmente, digna de nota.

Segundo, teorias da justiça distributiva podem dar valor à estabilidade e preferir, todo o restante sendo igual, as instituições mais propensas a alcançá-la. ${ }^{19}$ Teorias que endossem essa premissa não são indiferentes, portanto, à alegação de que certas normas jurídicas são mais tendentes do que outras a engendrar nos cidadãos virtudes que ajudem ou até sejam imprescindíveis a que a justiça se mantenha ao longo do tempo.

Ainda, pois, que suas conclusões estejam incorretas, a análise de Shiffrin tem a importância de chamar a atenção para a função distributiva decorrente da relação entre direito privado e virtudes. Tradicionalmente, análises sobre o papel distributivo do direito privado tratam as preferências dos agentes como exógenas, isto é, como independentes do conteúdo das normas. Tomemos como exemplo o artigo de Bruce Ackerman (ACKERMAN, 1971) sobre direito locatício. Ackerman descreve as condições sob as quais normas que instituam direitos de habitabilidade redistribuem renda em favor de inquilinos. Entre essas condições estão as preferências de inquilinos, pois é uma condição necessária para que a legislação sobre habitabilidade tenha efeito redistributivo que os senhorios não repassem seus custos para os

\footnotetext{
${ }^{18}$ Para Rawls (2001, p. 58), por exemplo, liberdades básicas devem ser garantidas à medida que se mostrem necessárias ao adequado desenvolvimento e pleno exercício de capacidades morais no que o autor chama de "dois casos fundamentais", a avaliação das principais instituições sociais segundo parâmetros de justiça e a definição de uma concepção de bem. Sobre a compatibilidade entre teorias liberais da justiça distributiva e a atenção às virtudes. Ver Rawls (2001, p. 140-145); Shiffrin (2007, p. 716-717).

${ }^{19}$ O exemplo proeminente aqui é Rawls (1999[1971], p. 6).
} 
inquilinos, o que depende, entre outros fatores, de que os inquilinos queiram arcar com um aumento do aluguel. Ackerman não cogita, porém, que as preferências dos inquilinos possam variar de acordo com o conteúdo do direito aplicável.

Outro exemplo proeminente de que o distributivismo costuma tratar as preferências como dadas é o artigo de Anthony T. Kronman (1980). Nele, o autor defende uma concepção de justiça distributiva aplicada aos contratos baseada no que chama de princípio do paretismo, segundo o qual o direito só deve permitir que uma das partes de um contrato obtenha certa vantagem (por exemplo, a vantagem de dispor de uma informação ignorada pela outra) se isso também beneficiar, a longo prazo, a maioria dos contratantes à custa dos quais a vantagem é obtida. Kronman também não considera que as preferências das pessoas em questão sejam uma função do conteúdo das normas, o que pode fazer com que o princípio do paretismo se mostre inconclusivo.

Considere, por fim, o famoso debate sobre o uso exclusivo do direito tributário para a distribuição de renda (KAPLOW; SHAVELL, 1994). A ideia de que objetivos quanto à distribuição de renda (quaisquer que sejam) devem ser perseguidos exclusivamente pela tributação não é incompatível, é claro, com a de atribuir a outras áreas do direito, entre elas o direito privado, um papel em relação às virtudes cívicas. A atenção que a tese da superioridade da tributação atraiu nos últimos anos, ${ }^{20}$ no entanto, é interpretável como sintoma de que o potencial distributivo do direito em geral diz respeito eminentemente à distribuição da renda, de modo que, provado que o direito tributário é um meio preferível para esse fim, pouco ou nada restaria a fazer por meio de outras áreas, inclusive o direito privado, quanto à justiça distributiva. Tal ilação não apenas ignora que há outros bens que não a renda cuja distribuição pode ser importante (KORDANA; TABACHNICK, 2005, p. 617-618; LEWINSOHN-ZAMIR, 2006), como também parece se basear em uma de duas premissas: a de que o direito não influencia as preferências dos cidadãos ou a de que tal influência é irrelevante. Do contrário, dificilmente se poderia cogitar que a superioridade da tributação como meio de distribuição de renda justifica eleger a eficiência como único objetivo do direito privado.

Para os interessados na relação entre direito contratual e justiça distributiva, a crítica de Shiffrin ao direito contratual norte-americano abre, portanto, uma nova linha de investigação. Ao invés apenas da medida com que os contratos atendem às preferências das

\footnotetext{
${ }^{20}$ Entre inúmeros trabalhos, ver Kaplow e Shavell (1994; 2000); Jolls (1998); Sanchirico (2001); Logue e Avraham (2003); Blumkin e Margalioth (2005).
} 
partes e de terceiros, teorias distributivistas talvez tenham de se preocupar com as virtudes que o direito contratual pode fazer aflorar nos cidadãos. Uma razão, como diz Shiffrin, é que essas virtudes podem ter importância distributiva em si mesmas (isto é, podem ser parte do que queremos ver distribuído). Outra é que elas podem ser imprescindíveis para a estabilidade de instituições justas.

\section{REFERÊNCIAS}

ACKERMAN, Bruce. Regulating slum houses on behalf of the poor: of housing codes, housing subsidies and income redistribution policy. Yale Law Review, v. 80, n. 6, p. 1.0931.197, 1971.

BARNETT, Randy E. A consent theory of contract. Columbia Law Review, v. 86, p. 269321, 1986.

BEN-SHAHAR, Omri; POTTOW, John A. E. On the stickiness of default rules. Florida State University Law Review, v. 33, p. 651-682, 2006.

BENSON, Peter. Abstract right and the possibility of a nondistributive conception of contract: Hegel and contemporary contract theory. Cardozo Law Review, v. 10, n. 5-6, p. 1.077-1.198, 1989.

BERNSTEIN, Lisa. Opting out the legal system: extralegal contractual relations in the diamond industry. Journal of Legal Studies, v. 21, p. 115-157, 1992.

BLUMKIN; Tomer; MARGALIOTH, Yoram. On the limits of redistributive taxation: Establishing a case for equity-informed legal rules. Virgina Tax Review, v. 25, p. 1-29, 2006.

BOWLES, Samuel. The moral economy: why good incentives are no substitute for good citizens. New Haven: Yale University Press, 2016.

CHARNY, David. Nonlegal sanctions in commercial relationships. Harvard Law Review, v. 104, n. 2, p. 373-467, 1990.

CHOU, Eileen Y; HAVELY, Nir; MURNIGHAN, J. Keith. The relational costs of incomplete contracts. Trabalho apresentado na 24 ${ }^{a}$ Conferência Anual da Associação Internacional de Gestão de Conflitos (International Association of Conflict Management), Istambul, Turquia, 2011. Disponível em:

http://papers.ssrn.com/sol3/papers.cfm?abstract_id=1872569. Acesso em: 13 jul. 2016.

FALK, Armin; KOSFELD, Michael (2004). Distrust - the hidden cost of control.

FALK, Armin; KOSFELD, Michael (2006). The hidden costs of control. American Economic Review, 96(5): 1.611-1.630. Instituto de Pesquisa para o Futuro do Trabalho

(Forschunginstitut zur Zukunft der Arbeit), Trabalho para Discussão n. 1.203, 2004. 
Disponível em: http://papers.ssrn.com/sol3/papers.cfm?abstract_id=560624. Acesso em: 11 jul. 2016.

FEHR, Ernst; LIST, John A. The hidden costs and returns of incentives - trust and trustworthiness among CEOs. Journal of the European Economic Association, v. 2, n. 5, p. 743-771, 2004.

FELDMAN, Steven V. Autonomy and accountability in the law of contracts: a response to Professor Shiffrin. Drake Law Review, v. 58, p. 177-241, 2009.

FISCHBACHER, Urs; GÄCHTER, Simon; FEHR, Ernst. Are people conditionally cooperative? Evidence from a public goods experiment. Economics Letters, v. 71, p. 397 404, 2001.

FRADERA, Véra Maria Jacob de. Pode o credor ser instado a diminuir o próprio prejuízo? Revista Trimestral de Direito Civil, v. 19, p. 109-119, 2004.

FREY, Bruno S. A constitution for knaves crowds out civic virtues. Economic Journal, v. 107, p. 1.043-1.053, 1997.

FRIED, Charles. Contract as promise: a theory of contractual obligation. Cambridge: Harvard University Press, 1981.

GNEEZY, Uri \& RUSTICHINI, Aldo. A fine is a price. Journal of Legal Studies, v. 29, p. $1-17,2000$.

GORDLEY, James. Equality in exchange. California Law Review, v. 69, n. 6, p. 1.587$1.656,1981$.

GREIF, Avner. Reputation and coalitions in Medieval trade: evidence on the Maghribi traders. Journal of Economic History, v. 49, n. 4, p. 857-882, 1989.

HEROLD, Florian. Contractual incompleteness as a signal of trust. Games and Economic Behavior, v. 68, p. 180-191, 2010.

JOLLS, Christine. Behavioral economic analysis of redistributive legal rules. Vanderbilt Law Review, v. 51, p. 1.653-1.677, 1998.

KAPLOW, Louis; SHAVELL, Steven. Why the legal system is less efficient than the income tax in redistributing income. Journal of Legal Studies, v. 23, p. 667-681, 1994.

KAPLOW, Louis; SHAVELL, Steven. Should legal rules favor the poor? Clarifying the role of legal rules and the income tax in redistributing income. Journal of Legal Studies, v. 29, p. 821-835, 2000.

KATZ, Avery. Virtue ethics and efficient breach. Suffolk University Law Review, v. 45, p. 777-798, 2012. 
KENNEDY, Duncan. Distributive and paternalist motives in contract and tort law, with special reference to compulsory terms and unequal bargain power. Maryland Law Review, v. 41, n. 4, p. 563-658, 1982.

KLIJNSMA, Josse. Contract law as fairness. Ratio Juris, v. 28, n. 1, p. 68-88, 2015.

KORDANA, Kevin A; TABACHNICK, David H. Rawls and contract law. George Washington Law Review, v. 73, p. 598-632, 2005.

KRAUS, Jody S. The correspondence of contract and promise. Columbia Law Review, v. 109, n. 7, p. 1.603-1.649, 2009.

KRAUS, Jody S.; SCOTT, Robert E. Contract design and the structure of contractual intent. New York University Law Review, v. 84, n. 4, p. 1.023-1.104, 2009.

KRONMAN, Anthony T. Contract law and distributive justice. Yale Law Journal, v. 89, n. 2, p. 472-511, 1980.

LEWINSOHN-ZAMIR, Daphna. In defense of redistribution through private law. Minnesota Law Review, v. 91, p. 326-397, 2006.

LIPSHAW, Jeffrey M. Objectivity and subjectivity in contract law: a Copernican response to Professor Shiffrin. Canadian Journal of Law \& Jurisprudence, v. 21, n. 2, p. 399-410, 2008.

LOGUE, Kyle; AVRAHAM, Ronen. Redistributing optimally: Of tax rules, legal rules, and insurance. Tax Law Review, v. 56, p. 157-258, 2003.

MARKOVITZ, Daniel; SCHWARTZ, Alan. The myth of efficient breach: new defenses of the expectation interest. Virginia Law Review, v. 97, p. 1.939-2.008, 2011.

MURPHY, Liam. Contract and Promise. Harvard Law Review Forum, v. 120, p. 10-18, 2007.

NORTH, Douglass C. Institutions, institutional change and economic performance. Cambridge: Cambridge University Press, 1990.

POSNER, Eric A. Economic analysis of contract law after three decades: success or failure? Yale Law Journal, v. 112, n. 4, p. 829-880, 2003.

POSNER, Richard. Economic analysis of law. 5. ed. Nova Iorque: Aspen, 1998[1973].

RAWLS, John. A theory of justice. 2. ed. Cambridge: Belknap Press, 1999[1971].

RAWLS, John. Justice as fairness: A restatement. Cambridge: Belknap Press, 2001.

SANCHIRICO, Chris William. Deconstructing the new efficiency rationale. Cornell Law Review, v. 86, p. 1.003-1.089, 2001. 
SCHEFFLER, Samuel. Distributive justice, the basic structure and the place of private law. Oxford Journal of Legal Studies (advance access), 2015, p. 1-23. doi:10.1093/ojls/gqu030.

SHIFFRIN, Seana Valentine. The divergence of contract and promise. Harvard Law Review, v. 120, p. 708-753, 2007.

SPIER, Kathryn E. Incomplete contracts and signaling. RAND Journal of Economics, v. 23, n. 3, p. 432-443, 1992.

TEPEDINO, Gustavo. Notas sobre o nexo de causalidade. Revista Jurídica, v. 296, p. 7-18, 2002.

WEINRIB, Ernst J. The idea of private law. Cambridge (EUA): Harvard, 1995.

WILLIAMSON, Oliver E. The economic institutions of capitalism: firms, markets, relational contracting. Nova York: Free Press, 1985. 